\title{
Integrating Different Data Sources to Address Urban Security in Informal Areas. The Case Study of Kibera, Nairobi
}

\author{
Francesca De Filippi ${ }^{1, * \mathbb{D}}$, Grazia Giulia Cocina ${ }^{1}$ and Chiara Martinuzzi ${ }^{2}$ \\ 1 Department Architecture and Design (DAD), Polytechnic University of Turin, 10129 Turin, Italy; \\ grazia.cocina@polito.it \\ 2 Planning, Finance and Economy Section, UN-Habitat, Nairobi 00100, Kenya; chiara.martinuzzi@un.org \\ * Correspondence: francesca.defilippi@polito.it
}

Received: 20 January 2020; Accepted: 18 March 2020; Published: 20 March 2020

\begin{abstract}
Nowadays, levels of crime and violence appear to be much higher in large cities in developing countries. This is the result of several factors, such as: the speed of urbanization, the inability of cities to provide sufficient infrastructure and the widening disparities in income and access to housing and services. These levels of inequality can have negative consequences from a social, economic and political point of view, with a destabilizing impact on societies and higher risks for the most disadvantaged people, especially those living in informal settlements. The paper presents the results of a study carried out by the Authors at the Department of Architecture and Design of the Polytechnic of Turin. Urban security is investigated in the context of Kibera slum (Nairobi) through the integration of two different tools, namely Participatory Mapping and Space Syntax. The research analyses the relation between criminal activities and the spatial and configurational features of the street network, with the aim to highlight some key environmental factors to take into consideration while constructing the new road Missing link \#12. Specifically, the research identifies and studies seven parameters from the literature review: integration, illumination, vitality and diversity, visibility, active facades, territoriality and maintenance and image. The findings show that urban planning and design strongly impact crime occurrence. The crime hot-spots' distribution in Kibera depends on the simultaneous interrelation of multiple components in the space.
\end{abstract}

Keywords: urban design; urban security; information and communication technologies (ICTs); space syntax; participatory mapping; slums

\section{Background}

Over the past two decades, there has been a marked increase in awareness of the need for innovative strategies and tools for crime prevention. That is well-reflected at the international level in the numerous conferences, resolutions and recommendations of the United Nations Commission on Crime Prevention and Criminal Justice since 1990. In particular, the work of international organizations such as the International Centre for the Prevention of Crime (ICPC), the United Nations Office on Drugs and Crime (UNODC) [1,2], and the World Bank together with the Inter-American Development Bank and the World Health Organization (WHO) [3] decided respectively to promote a comprehensive approach to crime prevention, by developing new tools and guidelines and by integrating improvements to local safety and security in their objectives and programmes.

UN-Habitat, within its programme "Safer Cities 2.0", aims to foster the implementation of Sustainable Development Goals (SDGs) and the New Urban Agenda through smart technologies. It is now widely recognized in fact, that without ensuring citizens' safety and security, the SDGs will not be 
achieved, and countries will not be able to gain economic and social prosperity [4]. Finally, the European Agenda on Security and the European Forum for Urban Safety focuses on improving information exchanges and operational cooperation between law enforcement authorities, mobilizing a number of EU instruments to support actions through training, funding and research and innovation [5].

Between 2002 and 2007 an average of $60 \%$ of urban residents in Africa and $70 \%$ in South America were victims of crime [6]. Therefore, the attention has shifted from the concept of "human security" to "urban security", considered more measurable, practical and constructive [3]. The shift also relates to the following findings [3]:

1. Large cities everywhere tend to have more crime and victimization than small cities.

2. In every country homicide rates grow with the relative size of its cities.

3. The rapid pace of urbanization and the resulting growth in city size and density is associated with increased street crime and violence but more so in developing countries than in developed countries.

4. Violent and other street crime tends to concentrate in certain parts of the city ("hot-spot") and neighbourhoods.

Other factors must additionally be taken into account while measuring urban security: culture, socioeconomic development, governance, the strength of civil society, etc.

At the local level, urban security problems can refer to various forms of crime (including human trafficking, organised crime, sexual violence, violence against vulnerable groups and minorities, theft and burglary, robbery, mugging and pickpocketing, vandalism, violent radicalisation and terrorism) and an actual or perceived lack of security. The perception of insecurity within a public space totally influences the social behavior between individuals and the community. It is therefore necessary to generate an urban environment capable of limiting the perception of insecurity and to encourage social interaction between people. To achieve this result, it is necessary to operate on different fronts: first of all, the design of physical space must minimize the elements that generate fear and allow its use by all citizens; secondly, the legislative and institutional framework must be able to regulate antisocial behavior and establish a relationship of mutual trust with the citizens; finally, the inhabitants must be involved through bottom up approaches [6].

\subsection{The Concept of Urban Security in Literature}

The relevance of the urban security topic is highlighted by the large number of authors who have dealt with it. In the 1960s and 1970s, two main theories emerged: Jane Jacobs' ideas, described in her book The Death and Life of Great American Cities [7] and Oscar Newman's theory of defensible space, in the homonym volume [8]. The authors argue about how a safe place and its natural policing should be planned. According to Jacobs, the streets do not belong only to cars, on the contrary, they together with the sidewalks constitute the most important public space: they represent the spaces of sociability and the "vital organs" of the city. Therefore, guaranteeing security on the streets would result in making the whole city safe. This process does not take place by strengthening the formal surveillance system but by generating a complex network of spontaneous and informal checks by the inhabitants themselves called natural surveillance. So, for Jacobs, permeable and open spaces, flows of people and activities increase the security of the area [7].

On the other hand, Newman suggests that it is possible to create a defensible space through physical layouts of residential areas that allow residents to better control them and that would discourage or deter potential criminals from committing their offenses in these areas. At the basis of this theory lies the concept of territoriality, according to which the inhabitants themselves must appropriate a certain place and feel the need to supervise it, discouraging strangers from entering the surveilled area. Indeed, Newman believes that population density and people congestion in public spaces creates anonymity, which improves the chances of criminals finalising their action [8]. 
In the same years in which Oscar Newman's theories were published, Ray Jeffery theorized the basic principles of Crime Prevention Through Environmental Design (CPTED) which took up several aspects discussed by previous theorists [9]. The four fundamental concepts that Jeffery summarizes are territoriality, natural surveillance, natural access control and space maintenance, highlighting some concrete measures that should be adopted in the practice of urban planning. Firstly, attention must be paid to visibility within a space: the presence of architectural obstacles or shaded areas prevents people from controlling it, increasing a feeling of insecurity. Together with visibility, lighting also plays a fundamental role. In fact, in addition to guaranteeing control of the space even during the night, it allows for the pointing out of the "safe" areas in which to move.

In 1991 Paul and Patricia Brantingham, with the publication Environmental Criminology [10], outlined the theory of the crime pattern [11] according to which people interact not only in space but also in time. The city is in fact broken down into nodes (activities that attract people), routes (roads usually chosen to move) and awareness areas (in which users move and interact consciously). According to this theory, criminals also have a familiar area in which they move and it is very likely that their actions take place within it.

The concept of familiar areas is also present in the routine activity theory of Felson and Cohen [12]. The authors explain that crime is likely to occur when an offender, an attractive target and the absence of capable guardianship converge in the same place and time. The research explained the crime rate changes in the United States between 1947 and 1974. The finding showed that an increase in opportunities (e.g., introduction of the car) changed citizens' routines, in terms of activities and movement, resulting in a change of previous crime patterns. [12].

In addition to designing safe spaces, G. Kelling and J. Wilson discuss the importance of space maintenance for crime prevention. Their broken windows theory [13] explains how a degraded environment affects the process of attachment of inhabitants to the environment itself. A building with broken windows invites the inhabitants to break others and therefore to worsen the initial situation. The carelessness of the authorities regarding the decorum and respect for a neighborhood reduces the interest of citizens to take care of it. In doing so, the principle of territoriality and natural surveillance is lacking and consequently the crime rate increases.

Finally, Bill Hillier deals with the topic of urban security in his book Space is the machine [14], in which an entire chapter "Can architecture cause social malaise?", is dedicated to the topic of urban security. According to the Space Syntax method, Hillier explains how the configurational characteristics of a space are essential in order to encourage or discourage a criminal act. In particular, the author states that public space can be described through a quantitative value called integration or the degree to which that space is integrated into the overall urban system. A road characterized by a high level of integration will also present a very high flow of people who walk it and it will be naturally surveilled, generating a virtual community. Hillier states: "If a space is designed wrongly, then natural patterns of social copresence in space are not achieved. In such circumstances, space is at best empty, at worst abused and a source of fear" [14]. According to Hillier, criminal or antisocial actions do not take place in the most segregated areas of the city but in the more integrated streets without natural surveillance. This is probably justified because the criminal complies with the movement logics of the inhabitant, who moves on the more integrated streets. He concludes by saying that a bad design of the public space creates possibilities in which a criminal action can take place and these can generate in users the perception of insecurity and fear, but it is not enough for a crime to happen.

\subsection{The Role of Technology}

During the last few years, the approach to crime prevention has changed from repressive to preventive, reducing the crime rate in different countries. Crime mapping is a well-established preventive discipline that uses statistical and geographic tools to study criminal events, often with the application of digital geographical analysis such as Geographical Information System (GIS) [15]. Through these systems, the mapping combines architectural-territorial information with diversified 
sources such as reports of reported crimes, video surveillance systems, public and private lighting, etc. In this way it is possible to carry out a more complex reading, to identify the most dangerous areas of a territory and to understand the causes.

In this context, technology is becoming increasingly important and new digital tools are at the service of crime prevention with a dual value. First of all, the use of sophisticated tools allows a more accurate reading of the territory and therefore the formulation of more specific strategies. Secondly, they represent a means of promoting more democratic and inclusive processes, which open up the possibility for citizens to actively participate in crime prevention policies.

Technology examples of the first type are Closed-Circuit Television (CCTV) [16] and crowd-counting system [17]. The most innovative tools for crime prevention are the predictive software that foresee in which areas of the city the future criminal event will take place $[18,19]$. Despite the conflictive methodology of using recorded past crime episodes to predict the most dangerous areas [20-22], predictive tools such as PredPol are transforming the police patrol system, particularly in the US [23].

On another hand, participatory tools for crime prevention are the transect walks, also called Safety Audits, which allow collecting information with respect to the perceived safety in a public space in relation to urban design and in order to propose intervention guidelines to improve safety [24-27]. Information and Communication Technologies (ICTs) also play a crucial role in crime prevention, by promoting more inclusive processes. The use of ICTs empowers citizens to act as decision-makers, by giving them the tools to consult and create reliable data about urban safety [28-30]. Examples of ICTs applications are voluntary mapping experiences such as Spatial Collective in the informal settlements of Nairobi [31], Miramap in Mirafiori Neighbourhood of Turin [28], Ushaidi during the post-election period in Nairobi [28,32], Emotional mapping in Olomouc, Czech Republic [33], Safetpin in the cities of Delhi, Bogota and Dhaka [34] and fixmystreet in the UK [35].

The use of various approaches allows a more accurate reading of the context and a specific understanding of the phenomenon. For this reason, two very different tools have been used in this research: the first is a forecasting one-the Space Syntax configurational analysis-and provides accurate information on the public space of the case study; the second is of an empirical nature-the participatory mapping of MapKibera Trust-and allows the democratization of the design processes through the direct involvement of the citizens. The information from these two sources has been combined in order to achieve a more complete interpretation of the study area and to understand the effects of comparing qualitative information with quantitative data with the aim to investigate the integration of these two different tools in enhancing crime prevention in informal settlements.

\subsection{The Application Context: The Slum of Kibera in Nairobi}

Nowadays, the levels of crime and violence appear to be much higher in large cities in developing countries. This is the result of several factors that create the ideal conditions for the realization of criminal facts, such as: the speed of urbanization, the inability of cities to provide sufficient infrastructure and the widening disparities in income and access to services among the population. These levels of inequality can have negative consequences from a social, economic and political point of view, with a destabilizing impact on societies and affecting the most disadvantaged people, especially those living in slums and informal settlements [27,36,37].

These are some of the reasons why the research focuses on the case study of the slum of Kibera in Nairobi (Kenya). Kenya emerged as a concerning context due the postelectoral violence of 2007, particularly experienced in slums such as Kibera [38-40]. Moreover, the inadequate stigmatisation of informal settlements as dangerous and violent places is also an aspect that proposed Kibera as a case study $[8,41,42]$.

From 1912, the Kenyan government informally conceded a land plot-Kibera-to Nubian soldiers, as a compensation for their service in the British army during the World Wars. With this agreement, soldiers had rights regarding the ownership of buildings but not regarding the land, causing extreme 
insecurity of tenure, especially after the 1950s when rural-urban migrations increased and Kibera expanded [43]. Located in the south-west of Nairobi city along the railway line and with an extension of $2.56 \mathrm{~km}^{2}$, today Kibera is one of the biggest informal settlements in Eastern Africa. With a density of about 90,000-100,000 inhab/ $\mathrm{km}^{2}[44,45]$, the settlement has limited public spaces, the street network is irregular, narrow and with fragmented lighting infrastructure, which reduce social interaction, visibility and safety. The overall physical components, the maintenance and the cleaning conditions are precarious.

In 2017 president Uhuru Kenyatta issued the Nubian community with a title deed for the original perimeter of the settlement [46]. However, the future development of Nairobi mobility shows the unbinding nature of the land deed. In July 2018 the construction of a new road started. The Missing Link \#12 was announced in January 2016 by the government of Kenya as a part of the Nairobi Integrated Urban Development Master Plan by 2023, a new proposal that will improve the traffic conditions of Nairobi. However, during the decision-making process, the community has not been adequately involved, causing the forced eviction of 11,500 residents and the closure or relocation of 13 schools [47].

This new connection completely transforms the current street configuration and the people movements in the informal settlement. The research aims to study the impact of the Missing Link \#12 on the current Kibera crime patterns, to understand the relation between space and urban security. To achieve this objective, an innovative methodology that combines qualitative information and quantitative data has been developed.

\section{Research Methodology}

The research integrates the relation between crime distribution and spatial features of the public space in Kibera. Different data should be studied to adequately understand the phenomena. However, National Police Service of Kenya documents only nation-wide statistics, while spatial data at the city or neighbourhood scale are not available [48]. Moreover, official crime data emerged to be questionable when compared with other countries [49] and other sources [40]: a UN-Habitat city-wide crime survey interviewed 7954 residents of Nairobi and 37\% of respondents declared to had been victims of robbery and $29 \%$ of burglary, at least once during 2001 . These numbers are not consistent with the national reports and discrepancies are probably related to an inadequate official crime monitoring system, as well as a limited reporting activity by the citizens. The survey estimated that $30 \%$ of Burglary cases were not reported, due to the lack of trust in the justice system and the police forces [40]. Figure 1 lists some of the reasons stated by the interviewees. Finally, the Nairobi city-wide crime survey conducted in 2002 under-represented informal settlements [40].

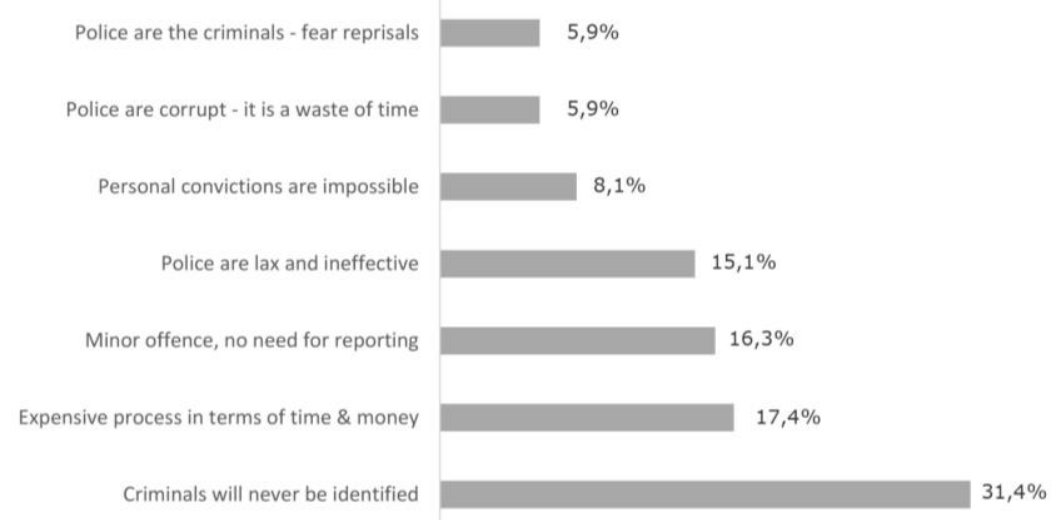

Figure 1. Reasons stated from the residents who did not claim to the police a house robbery (Elaborated by the Authors, from the data of the source [40]).

The authors consulted other data sources, such as voluntary mapping. Crowdsourcing platforms have been already recognized as a powerful tool to gather qualitative data about security and safety, 
valuing citizens knowledge [30,50,51]. These mechanisms have been used by local governments to implement policies and interventions to improve urban safety in different contexts [50,52-54]. Therefore, the research considers voluntary mapping records as the most reliable data source of crime patterns in Kibera.

Through this approach, the analyses are based on a dataset that integrates two different data sources: MapKibera Trust participatory mapping and Space Syntax analyses. On one hand, the participatory mapping conducted by MapKibera Trust, based on interviews, exploratory walks and discussion groups with the slum dwellers, provides empirical, qualitative and specific data about urban security in Kibera. With these inputs, the research benefits from the direct and unique experience of residents, considered as "experts of knowledge" of the informal settlement [55,56]. On the other hand, the configurational analyses of Space Syntax produced by the authors provide quantitative and verifiable information about people movements through the public space. Following the rigorous Space Syntax methodology, it is possible to forecast remotely reliable scenarios of movement, integrating physical and social aspects of the space without needing a direct experience.

Drawing upon the literature studied, a few parameters have been identified to analyse the relation between the physical space and crime occurrence. Specifically, the parameters identified are integration, illumination, vitality and diversity, visibility, active facades, territoriality and maintenance. Several authors agreed that these spatial components ensure safe and vibrant public spaces and reduce the possibility of criminal actions [7-14].

Based on each principal, different analyses have been carried out to investigate specific physical and configurational aspects of the public space. Specifically, the study unit is the immediate surroundings of the hot-spot area; however, statistic comparisons at the settlement level have been carried out to identify recurrent patterns. In this way, each theoretical concept has been translated in tangible and concrete elements of the space to be studied in this research. In the following Table 1, the seven parameters are explained in more detail.

Table 1. Spatial parameters of the public space related to urban security.

\begin{tabular}{|c|c|c|}
\hline Parameter & Theoretical Principles & Tangible Application \\
\hline Integration $[7,12,14]$ & $\begin{array}{l}\text { The integration value describes the } \\
\text { movement potential of a public space within } \\
\text { a spatial configuration. A high integration } \\
\text { value represents high flow of people and thus } \\
\text { good level of natural surveillance. }\end{array}$ & $\begin{array}{l}\text { The integration value of hot-spot street } \\
\text { segments is analysed to verify the relation } \\
\text { between movement potential and } \\
\text { crime occurrence. }\end{array}$ \\
\hline Illumination [6-9] & $\begin{array}{l}\text { A good level of illumination ensures safety } \\
\text { and security during the night. }\end{array}$ & $\begin{array}{l}\text { The illuminated area within the public spaces } \\
\text { is drawn, considering the typology and the } \\
\text { height of the street lighting system. Then, the } \\
\text { hot-spot location in relation with this area } \\
\text { is analysed. }\end{array}$ \\
\hline $\begin{array}{l}\text { Vitality and diversity } \\
\qquad 6-12]\end{array}$ & $\begin{array}{l}\text { A vibrant and multifunctional environment } \\
\text { ensures the presence of a continuous and } \\
\text { diverse group of people surveilling the space } \\
\text { and limiting antisocial behaviour throughout } \\
\text { the day. }\end{array}$ & $\begin{array}{l}\text { The number and the variety of nonresidential } \\
\text { use within a certain radius of distance from } \\
\text { the hot-spot, to verify whether crimes mainly } \\
\text { occur close to specific activities. }\end{array}$ \\
\hline Visibility [6-9] & $\begin{array}{l}\text { The visibility of a public space depends on } \\
\text { the building configuration, the street section } \\
\text { and the urban furniture. The higher is the } \\
\text { visibility, the better the natural surveillance. }\end{array}$ & $\begin{array}{l}\text { The public spaces with high visibility are } \\
\text { identified as safe spaces and thus where } \\
\text { people mainly move. The visual distance } \\
\text { (Step Depth Analysis with Space Syntax) } \\
\text { between these and the hot-spot is analysed to } \\
\text { understand whether criminals act in visually } \\
\text { connected area or not. }\end{array}$ \\
\hline Active facades [6-9] & $\begin{array}{l}\text { The building facades provide natural } \\
\text { surveillance, due to the visual connection of } \\
\text { indoor and outdoor spaces through windows, } \\
\text { doors and any building openings. }\end{array}$ & $\begin{array}{l}\text { Each building opening facing a hot-spot is } \\
\text { identified and classified in terms of } \\
\text { dimensions and material (solid, transparent). } \\
\text { Then, the isovist analysis (with Space Syntax) } \\
\text { verifies the surveillance potential of each } \\
\text { opening. This allows us to verify whether the } \\
\text { presence of building openings discourage } \\
\text { crime occurrence or not. }\end{array}$ \\
\hline
\end{tabular}


Table 1. Cont.

\begin{tabular}{|c|c|c|}
\hline Parameter & Theoretical Principles & Tangible Application \\
\hline Territoriality [8-11,13] & $\begin{array}{c}\text { The building thresholds between private and } \\
\text { public area enable inhabitants to appropriate } \\
\text { public space segments and increase } \\
\text { surveillance of the surrounding space. }\end{array}$ & $\begin{array}{c}\text { Intentional and unintentional elements that } \\
\text { generate thresholds (urban furniture, } \\
\text { vegetation, fences, drainage lines) between } \\
\text { private and public space are analysed to } \\
\text { understand whether crime occurrence is } \\
\text { discouraged or not. }\end{array}$ \\
\hline $\begin{array}{c}\text { Maintenance and stigma } \\
{[6,8,9,13]}\end{array}$ & $\begin{array}{c}\text { Good level of maintenance managed by } \\
\text { authorities or citizens increases community } \\
\text { identification with its own neighborhood and } \\
\text { thus its interest in taking care of the public } \\
\text { space and surveilling it. }\end{array}$ & $\begin{array}{c}\text { The conversation condition of building and } \\
\text { pavements around the hot-spot is analysed to } \\
\text { define linkages between crime occurrence } \\
\text { and level of maintenance. }\end{array}$ \\
\hline
\end{tabular}

Here below are briefly described the two different data sources that are the basis of research analyses.

\subsection{Participatory Mapping of MapKibera Trust}

MapKibera Trust is a community-based organisation that aims to share information about Kibera with the people living inside and outside the settlement through voluntary mapping and participatory journalism. Founded in 2009 based on the pilot project of Erica Hagen and Mikel Maron, MapKibera Trust developed the first public map of the settlement and produced several thematic maps considering the urgent issues of the settlement, such as water and sanitations, education, health and security. The first security map of MapKibera Trust was completed in 2010 —updated afterwards in 2013 and 2017- on response of the postelection violence in 2007, to monitor and inform residents about safe and unsafe areas within the slum [57,58]. Arguing about criminality in Kibera, MapKibera Trust explains that the main causes are related to extreme poverty and unemployment. Indeed, $60 \%$ of youth is unemployed and crime rates are high [55].

As illustrated in Figure 2, the map gathers elements such as: street lighting, bars police stations, gender-based violence support centers, chief camps-informal community groups providing security around the neighbourhood-and other organisations. These aspects are strongly related to security. For instance, alcohol sale often is related to fear or insecurity within the public space in informal contexts [36]. The map also identifies the hot-spots of Kibera reported by the community: Crime activities reported in the hot-spots are pickpocketing, robbery, mugging, murder or rape. Furthermore, several hot-spots marked an increased risk during the night. Specifically, 37 hot-spots are reported in the security map, of which 15 have an increased risk at night.

The term hot-spot has several definitions [59]. In this research, hot-spot refers to "an area that has a greater than average number of criminal or disorder events, or an area where people have a higher than average risk of victimization" [59].MapKibera Trust defines hot-spot as "a dangerous place where more than one criminal activity has been reported" [57,60]. Specifically, MapKibera Trust distinguishes two types of hot-spot: black-spots-dangerous places where more than one criminal activity has been reported-and hatari-spot-potential unsafe places considering their physical and spatial features. However, in this research both are considered as hot-spotspots. 


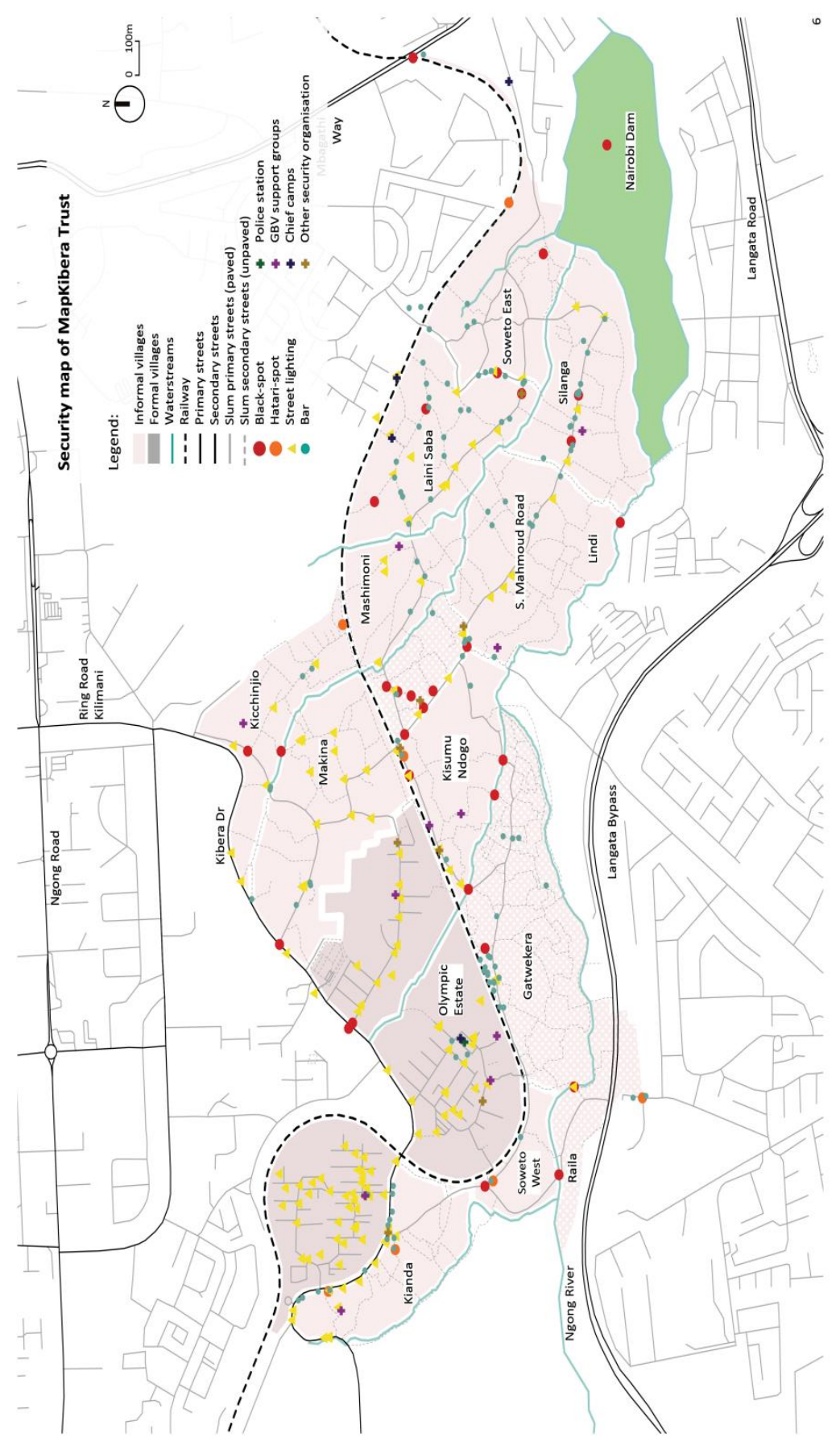

Figure 2. Security map of Kibera Slum (Elaborated by the authors, from the data of MapKibera).

\subsection{Space Syntax Analyses}

Before analysing the elaborated data, it is important to describe the Space Syntax approach, developed in the 1970s by Bill Hillier and Julienne Hanson at the Barlette School University of London. Space Syntax theories analyse the configurational features of space and their relationship with social and antisocial behaviours, defining people movements. As previously explained, this information is relevant in urban security studies for two main reasons: firstly, people flow ensures the presence of a virtual community in the public space providing continuous natural surveillance; secondly, it is also a flow of potential victims, which are highly targeted by criminals [14].

In deepening one's understanding of the Space Syntax theory, two main concepts should be described: configuration and integration. A configuration is a network of connected spaces. It is a 
specific system of relations connecting a certain amount of spaces, considering their sequence-whether they are adjacent or not—and permeability—whether they are joint or not—and regardless of their geometrical features. Once the relation between two or more spaces is changed, the entire configuration is considered as different. Space Syntax quantifies the connectivity of a space with the integration value. A space is highly integrated when it benefits from a well-connected position in the configuration in relation to every other space. Specifically, the integration value is the calculation of how close or how accessible each spatial element is in relation to all the others and it assesses its potential movement as destination-how many people would go there as final destination-also called the to-movement potential [14]. Similarly, the integration value also measures the potential of visibility of a space. For instance, the hallway of an apartment or the salle commune of an 18-century French villa are both highly integrated spaces within their system, due to their central position in the configuration, generating dense flows and high visual connection [14].

The Space Syntax approach has different methods to study configurational features. For instance, the Axial Map Analysis and the Visibility Step Depth Analysis provide information regarding the integration values of a network of spaces. Specifically, an Axial Map describes a spatial configuration through axial lines, which are the longest lines inscribable in a convex space. Running the analysis of an Axial Map, each line receives a color describing its integration value according to the sum of steps required to move from the analysed space to every other space of the configuration: red represents high integrated space with the lower number of steps, while blue describes low integrated spaces with higher number of steps [61,62]. Thus, people mainly move in red highly integrated lines. Similarly, Visibility Step Depth describes the visual integration of a space, studying the isovists, which are visible areas from a specific point. Overlapping each isovist generated from every point of the space, the visual integration values are elaborated. The Visibility Step Depth Analysis counts the number of visual-steps between two specific spaces and thus defines the visual distance between two points. Red areas are visually-high integrated, while blue ones are visually-low integrated. [63-65].

In this research, Space Syntax analyses provided the integration values of Kibera's public spaces-and thus the current flow of people-before the construction of the new road Missing Link \#12. These data have been integrated with the security map of MapKibera Trust to analyse the relation between space and urban security in the informal settlement. The research also studied the integration values of Kibera's public space after the construction of the new road, as a starting point to interpret the future urban security of the slum.

The following describes in detail the data elaborated by the authors with Space Syntax analysis: firstly, the Axial Maps of Kibera's public spaces before and after the Missing Link \#12; and secondly, the Visibility Step Depth related to the current configuration of the slum. The maps were developed with QGIS Space Syntax Toolkit based on OpenStreetMap (OSM) data. When information regarding the built environment lacked in OSM, satellite images and Google and Mapillary street views were used.

Figure 3 shows the current integration values of Kibera and its surrounding. It is important to show Kibera within a larger context, to limit the edge effect [14]. Moreover, the introduction of the Missing Link \#12 impacts the entire city network. Usually, Space Syntax focuses only on spaces where vehicles and/or pedestrians move. In Kibera the railway line is used as footpath by many inhabitants and it represents a vibrant place for small businesses, due to the limited number of trains travelling on it. Thus, the railway is considered part of the street network and it is analysed. The main flows are highlighted in red (Ngong Road, Ring Road Kilimani, Mbagathi Way, Kibera Drive, Sheikh Mahmoud Road), while the more segregated segments are in blue (short and irregular secondary path far from the main streets). The section of the railway within Kiberais also marked in red and this aspect highlights its importance in the street network. 

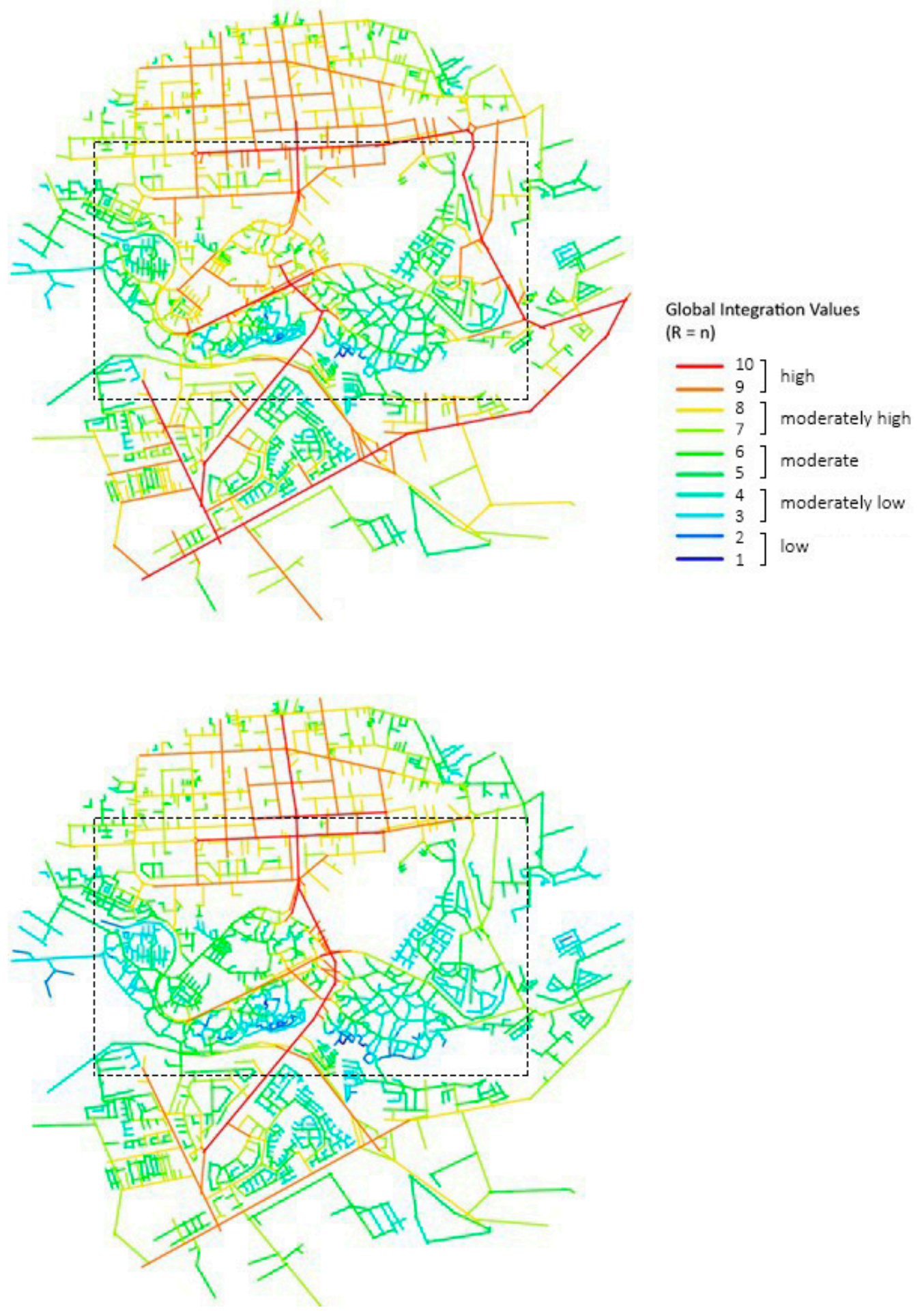

Figure 3. Axial maps of the current (top) and the future (bottom) configuration of Kibera public spaces (Elaborated by the authors).

Regarding the future configuration, the information about the Missing Link \#12 project is very limited and it is not yet specified which will be the relation between the new road and the preexisting street network. Thus, the streets layout was modified introducing the new connection and eliminating paths demolished in July 2018. It is assumed that all the intersections between new and old lanes will be permeable, excluding the railway junction [47]. While in the first configuration the city traffic was congested among the main roads around Kibera, the introduction of the Missing Link \#12 improves 
the mobility conditions of Nairobi. The new connection is likely to improve the integration of the settlement within Nairobi, resulting in an increment of opportunities for slum dwellers.

Finally, in Figure 4 a sample of the Visibility Step Depth Analysis of Kibera's public spaces is shown. Rectilinear streets with wide sections such as Sheikh Mahmound Road, Ali Jaden Road and the railway line have high visual integration value, while irregular secondary paths with narrow section are visually low integrated.

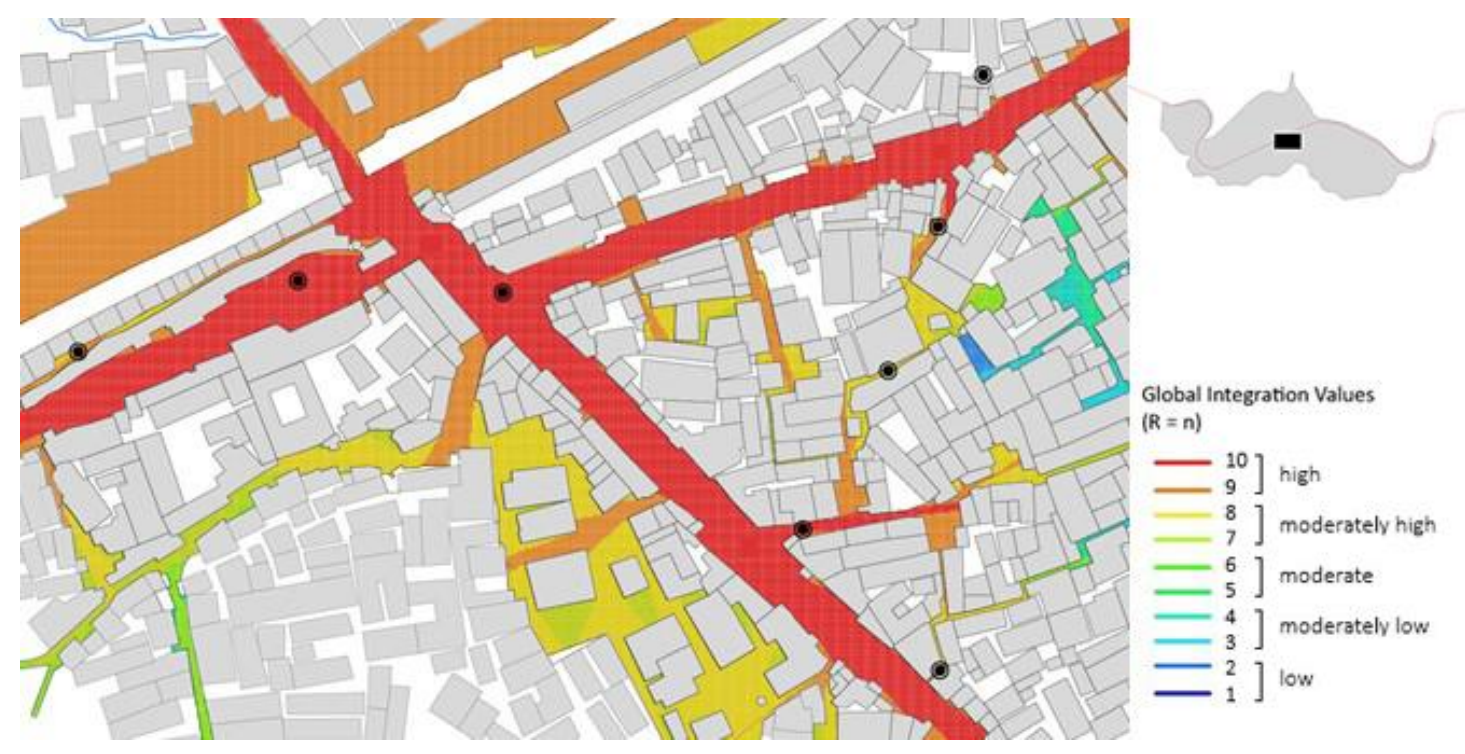

Figure 4. Visibility Step Depth Analysis of Kibera public spaces (Elaborated by the authors).

\section{Analysis}

Below the analysis of the integrated data about Kibera public spaces and urban security is reported. Each analysis focuses on one of the environmental parameters listed before. For each principle, few physical elements of the space were observed and discussed at different scales. Some parameters were analysed at the territorial or local level, while others at both. The term territorial in this research means considering the entire slum system, while local refers to specific focus areas of the settlement, which are the immediate surroundings of the hot-spots. For instance, the parameter of integration is relevant at the territorial scale, because it studied the whole street network of the slum; on the other hand, territoriality and active facades are strongly related to urban and architectural design and thus are analysed at the local level; finally, visibility has interesting applications at both scales.

This article reports the main findings of the territorial analyses regarding integration, illumination and visibility, while for the local analyses it describes all the parameters. These analyses propose some key insights to guide actions and strategies on urban security for the future development of Kibera, after the introduction of the Missing Link \#12.

\subsection{Territorial Analysis}

As shown in Table 1, different spatial principles were identified from the literature reviewed and translated in tangible spatial components of the public space to analyse the current urban security of Kibera. Regarding the territorial scale, three parameters are deepened: integration, illumination and visibility (see Figure 5). 


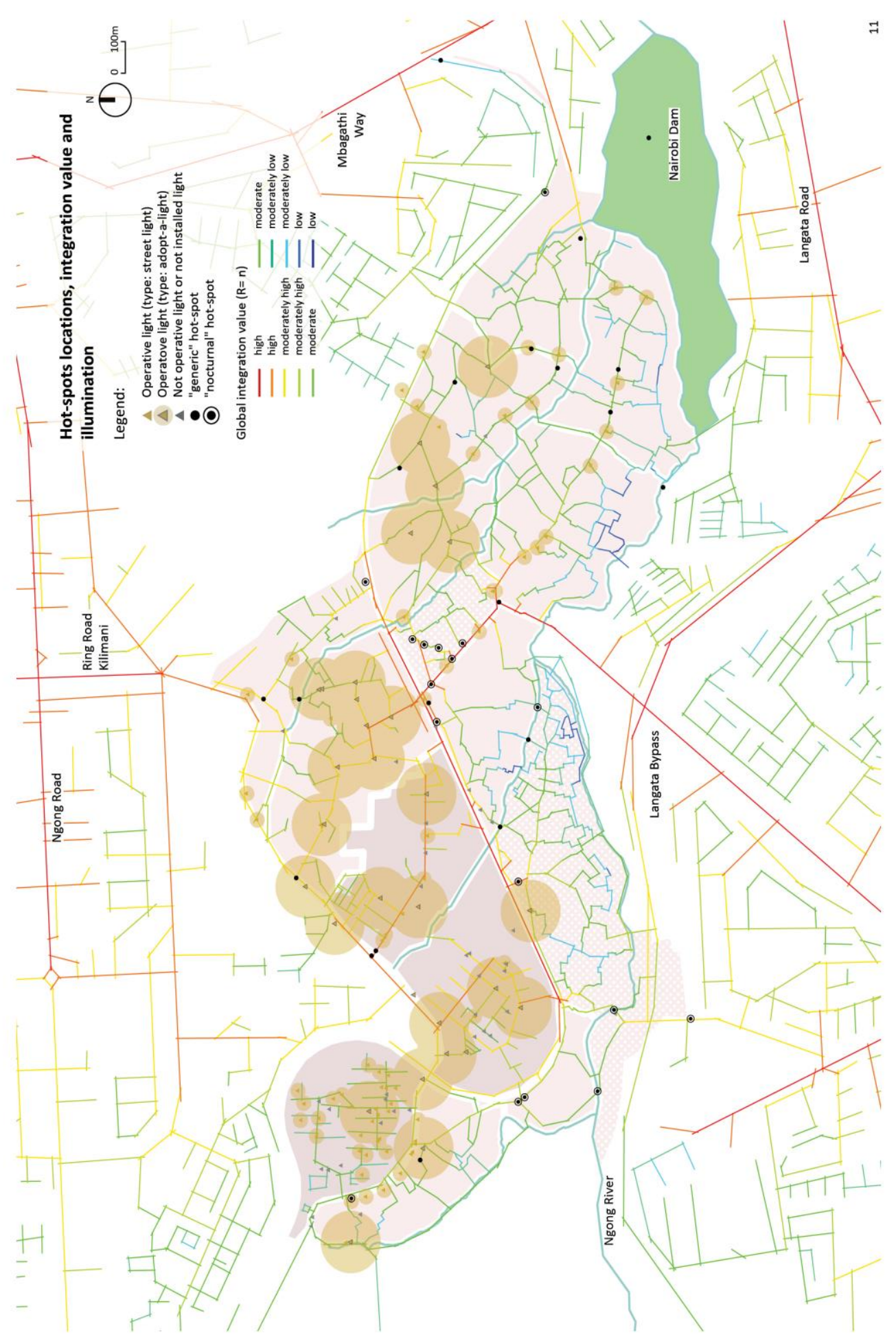

Figure 5. Correlation between crime, integration and illumination in Kibera (Elaborated by the authors).

Firstly, the relation between hot-spot locations and integration value of street sections is analysed, to understand the influence of the integration parameter in crime occurrence. Each hot-spot mapped by MapKibera Trust receives the integration value of the street section in which it is located. The integration values of the street sections are calculated through the Axial Map Analysis, elaborated by the authors. Furthermore, 3.5\% of hot-spots are located in high integrated street (red and orange); while $54 \%$ have a moderately high integration value (yellow and light green); $40.5 \%$ have a moderate integration value (light green and green) and 10.8\% have a low integration value (light blue and blue). It could be argued 
that location of hot-spots in Kibera is influenced by the integration parameter. Specifically, hot-spots are mostly placed on moderately high-integrated street sections. This distribution is consistent with the findings of Hillier studies $[14,66]$, as well as the routine activity theory [12]: street sections with moderately high integration values mainly coincide secondary path directly connected to main flows corridors, where attractive targets and limited capable guardship are offered to motivated offenders.

Secondly, the impact of illumination in urban security is analysed by comparing the hot-spot location and the illuminated area of Kibera. MapKibera Trust has mapped all the light sources in the public spaces, providing additional information regarding the maintenance status (operative, not operative or not installed) and the typology (street light or adopt-a-light [67]). In this analysis, only the functional lighting sources were considered. Each operative lamp covers an area, depending on the typology: while the street lights are installed at an estimated height between 5 and $8 \mathrm{~m}$ (estimate considering Google Street View) and cover an approximated area of 20-m radius, the adopt-a-light masts are almost 20-m high and their lighting power decreases after a radius of $100 \mathrm{~m}$ [68]. In this way, the current illuminated public space area is drawn and it represents $29.5 \%$ of the Kibera public spaces area. Consequently, $30 \%$ of hot-spots should overlap with the illuminated area to have an equal distribution. However, only $16 \%$ of hot-spots overlap with the illuminated areas and $84 \%$ of hot-spots remain in the dark zones. Therefore, it could be argued that lack of illumination is an influencing factor for prone-crime areas.

Finally, the relation between crime occurrence and visibility is analysed. To do this, the Visual Steps Depth between hot-spots location and the closest visually high-integrated street is measured to understand the visual distance between hot-spot and safer areas. The assumption that spaces with good visibility are safer and people mainly walk on safer streets is based on the literature review of crime prevention [6-9]. In overurbanised informal settlements such as Kibera, open public spaces are limited and good levels of visibility are rarely achieved. The Visibility Step Depth Analysis of Kibera (extract in Figure 4) shows that the main visually integrated spaces correspond to the main streets, wide enough to allow vehicular transits. In addition, $54 \%$ of hot-spots are located in areas with 0 visual step from visually high-integrated spaces, while $21.6 \%$ have 1 visual step distance and $24.4 \%$ have 2 or more visual steps. Therefore, it could be argued that hot-spots in Kibera are visually well-connected to safer areas, probably due to the need for criminals to monitor movement of potential targets. This finding is contradictive with the basic assumptions. However, the fragmented and irregular shape of public spaces and streets in Kibera offers to criminals ideal microenvironment to easily hide themselves from targets. In addition, $50 \%$ of the hot-spots directly connect with safer areas ( 0 visual steps) are located close to street junctions, as shown in Figure 4. Junctions are strategic locations for crime occurrence, because the criminal can monitor movement of upcoming targets remaining out of their visual field. Analysing these aspects through the crime pattern theory [12,69]: crime occurs when offenders and targets share the same awareness area. Criminals act in familiar zones and know which are the main attractive nodes and the personal paths generally used by targets.

\subsection{Local Analysis}

To deepen the findings at the large scale, the following local analyses have been developed on a specific area of the settlement located on the crossing between Sheikh Mahmoud Road, Ali Jaden Road and the railway line. The focus area, illustrated in Figure 6, represents a strategical point of Kibera spatial configuration, where people movements are overlapped. The focus area selection depended on the peculiar concentration of hot-spots and on the findings of the territorial analyses. Indeed, as shown in the previous maps, the integration values, the illumination conditions and the visibility features draw optimal conditions for crime occurrence. The following analyses and compares the location of two hot-spots and their surroundings. The first is placed at the junction between two main roads and has a high integration value (red, while the second is located on a secondary road, visually connected with the main integrated space and with a moderately high integration value (light green). The hot-spots selected are adequately representative among the others, as emerged in the territorial 
analysis, and thus it is possible to draw some general conclusions about crime patterns in Kibera at the local level.

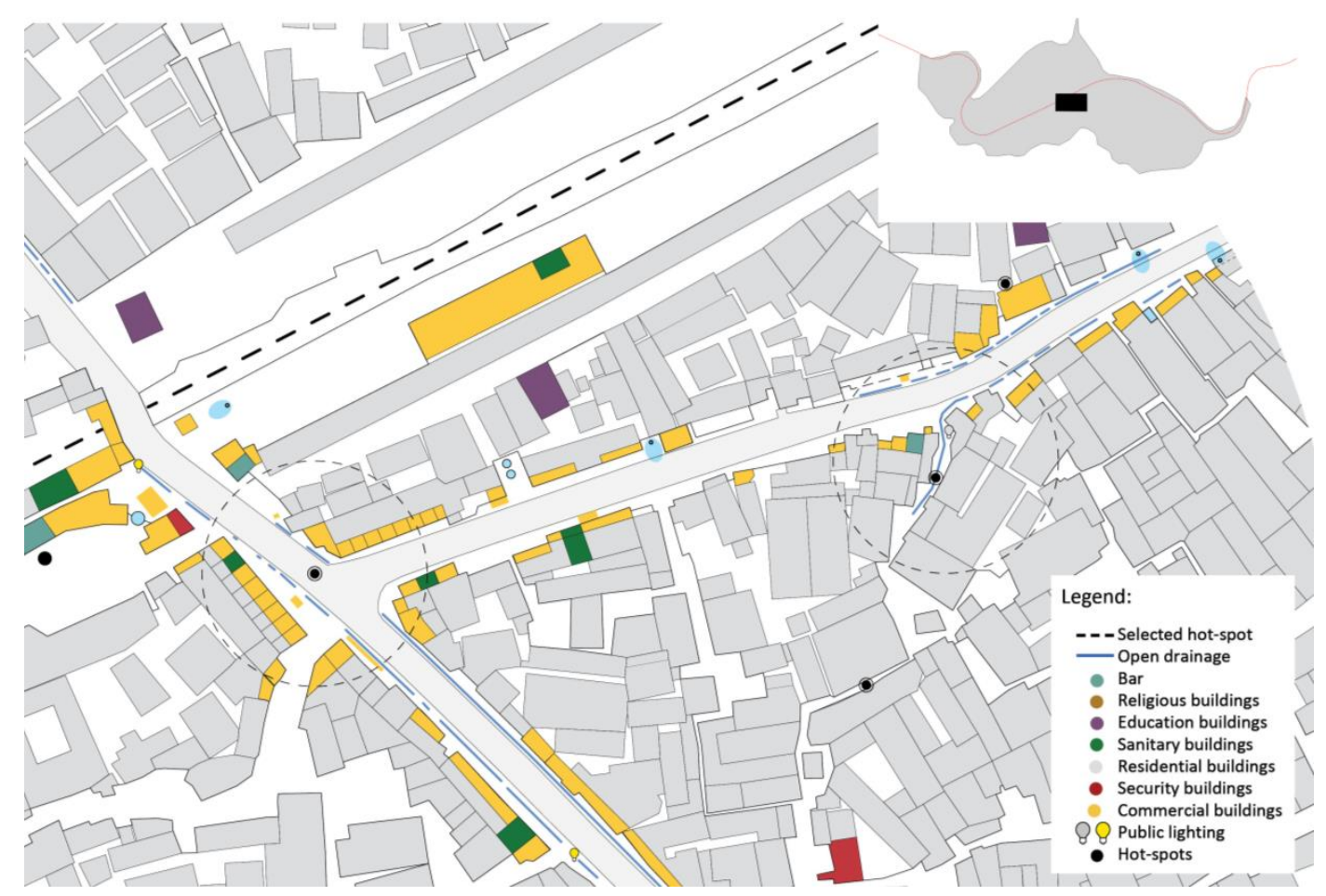

Figure 6. Focus area for the local analyses (Elaborated by the authors).

The hot-spot areas were analysed considering the research parameters of vitality, natural surveillance and visibility. The first parameter focuses on the formal and informal activities located in the analysed area. Jacob and several authors argue about the importance of vitality and diversity to ensure a continuous and natural patrol of the public space by the community. Most of the data has been collected by MapKibera Trust, specifically regarding educational, sanitary, religious and security buildings. The authors integrated this information with the commercial activities, mapped with Google and Mapillary street views. Secondly, the natural surveillance analyses the number and the typologies of openings facing the public space. Indeed, the visual connection between indoor and outdoor spaces increases the natural surveillance and thus the security of the public open space. The third parameter analysed is visibility and, through the Isovist Analyses run with Space Syntax, the patrolled area covered by "the eyes on the street" was defined, as the sum of every Isovist related to an opening in the public space. To ensure a more accurate result, for each opening typology a different visual angle, from $90^{\circ}$ to $180^{\circ}$, has been assigned. Finally, the security of the public space is also highly related to the quality of the space in terms of design and maintenance [11].

\subsubsection{Hot-Spot 1}

ID code: 712892550

Note of MapKibera Trust: “Dangerous place, people cannot pass at night" (MapKibera, 2018)

Crime: Unspecified

Hot-spot classification: Black-spot, with increased risk during the night

Location: The hot-spot is located on the crossing between Sheikh Mahmoud Road and Ali Jaden Road, close to the bridge over the railway. The area is a strategic point of the Kibera flows of people and intersect four secondary paths (see Figures 7 and 8).

Street conditions: Paved

Street section: $1.25 \mathrm{~m}$ 


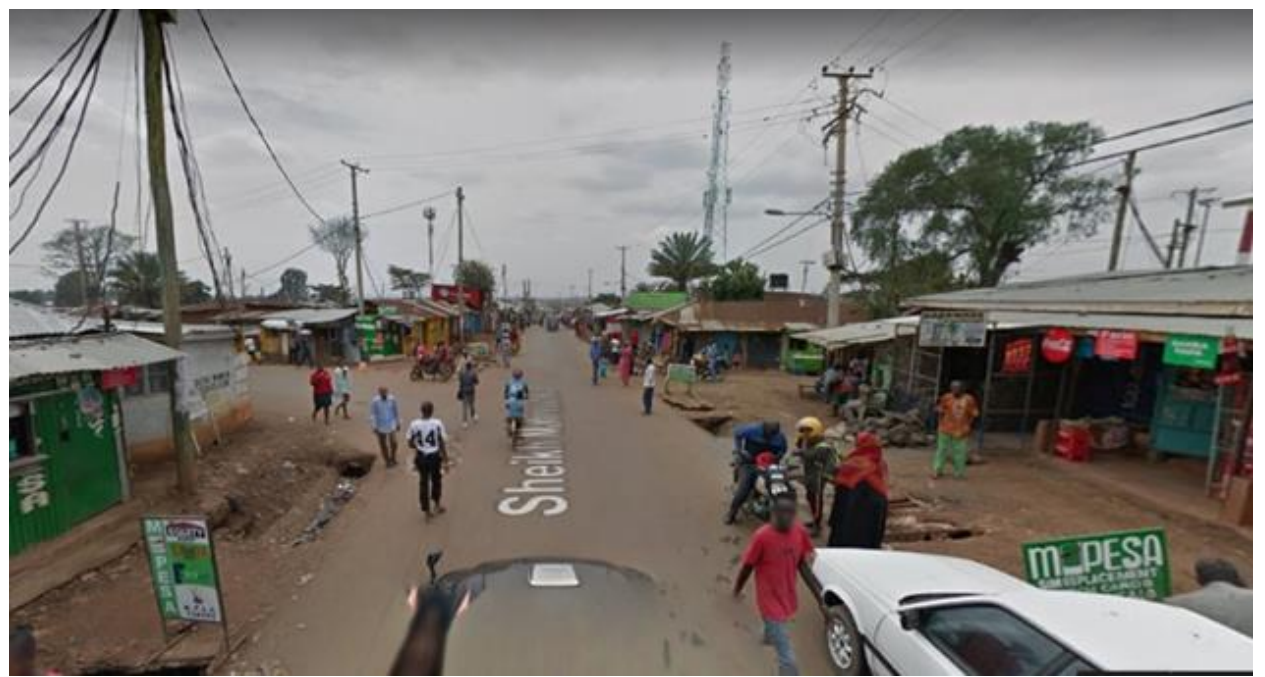

Figure 7. Street view of hot-spot 1 (source: Google maps street views).
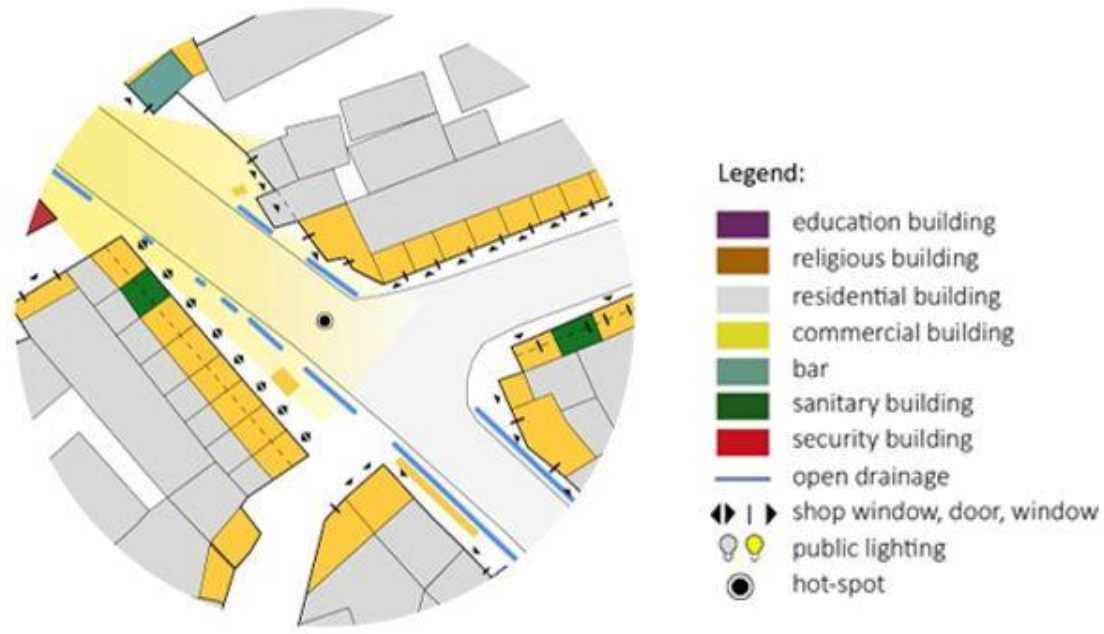

Figure 8. Hot-spot 1 (Elaborated by the authors).

Integration (Figure 9): This is the only hot-spot located on the most integrated line (red) of Kibera and it is an exception from Hillier's theories, suggesting that criminals generally avoid the highest integrated segments [14].

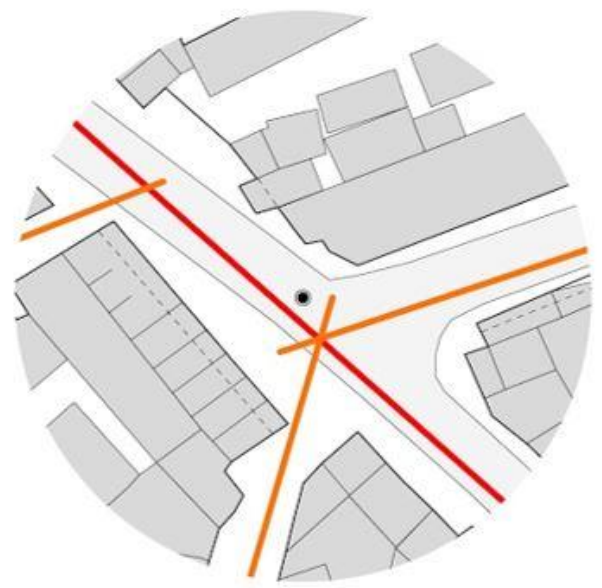

Figure 9. Hot-spot 1: integration map (Elaborated by the authors). 
Illumination (Figure 10):

Light typology: street light

Light source: four bulbs with different orientation. Bulb body opening $>90^{\circ}$

Status: Operative

Distance from hot-spot: $46 \mathrm{~m}$

Estimated height of mast: $7.5 \mathrm{~m}$

The typology and the estimated heights of the lighting source show that the hot-spot does not benefit from the lighting power.

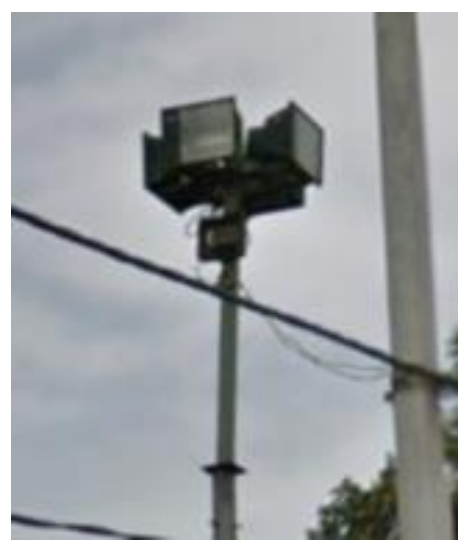

Figure 10. Hot-spot 1: light source (source: Google maps street views).

Vitality and diversity: The area presents several commercial activities and a variety of services, due to its strategic position in the slum configuration. Buildings directly facing the hot-spot are mainly shops with diurnal opening hours. However, this aspect highlights a considerable discrepancy between day and night: while during the day, the area attracts high people movements both for its spatial configuration and the high amount of activities resulting in a high level of natural surveillance, in the night most of the activities are closed (there is one bar open) and no residential unit keeping the space monitored.

Active facades (Figure 11): The area benefits from active facades that have a variety of openings connecting public and private. Shops of Kibera are considerably micro units and have mainly three different typologies: the first one has the front wall open as a shop window (a), the second one allows clients to enter the shop through a door (b) and the third one interacts with outsiders through a window (c), often barred.

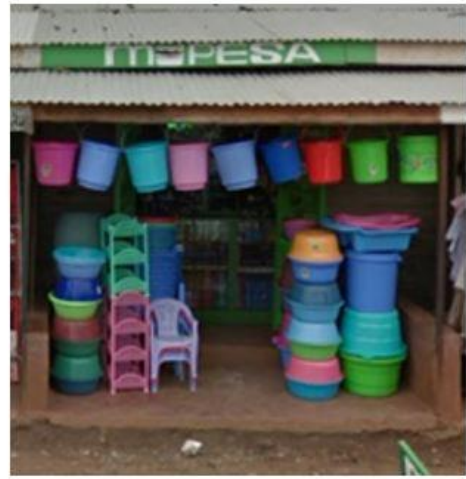

(a)

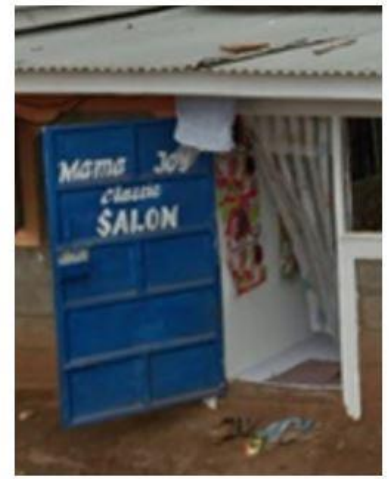

(b)

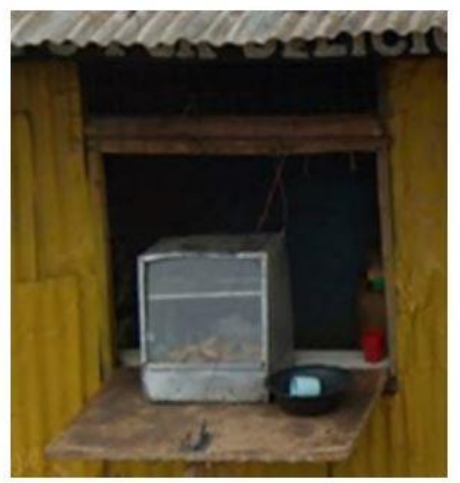

(c)

Figure 11. Hot-spot 1: opening typologies. Shop window (a), door (b), and window (c) (source: Google maps street views). 
Shop windows are a natural extension of the shop to the immediate outside area. Since the seller spends a substantial about of time outside of the unit, this typology generates a high level of natural surveillance among the public space (isovist angle $=120^{\circ}$ ).

Doors mainly have two purposes: in the third shop typology, it allows the seller to enter the unit, but it remains closed most of the day (isovist angle $=45^{\circ}$ ). While in the second shop typology, it allows people movement and thus generates a moderate level of natural surveillance among the public space (isovist angle $=90^{\circ}$ ).

Commercial windows generate natural surveillance among the public space, because the seller constantly keep its attention to the external area (isovist angle $=90^{\circ}$ ). On the other hand, residential windows are often covered with solid material to increase privacy inside the unit and therefore provide a limited level of surveillance (isovist angle $=45^{\circ}$ ).

Visibility (Figure 12): Hot-spot visibility from the building's openings is verified by the Isovist analysis with Space Syntax. Each opening has a correlated isovist with a specific angle (see angle above). Overlapping the isovists, it is evident that the hot-spot is highly monitored during the day, while in the night the activities open are not visually connected and thus do not provide adequate surveillance.

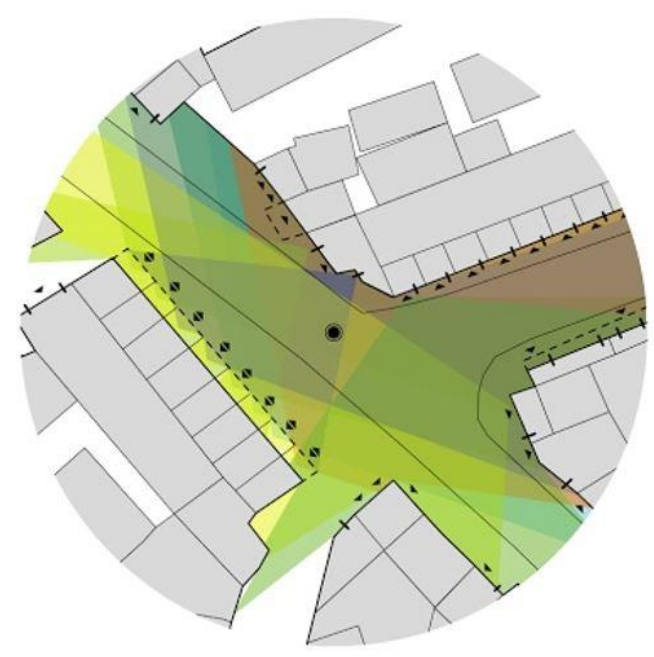

Figure 12. Hot-spot 1: isovists map (Elaborated by the authors).

Territoriality (Figure 13): Oscar Newman's theories explain that intentional and unintentional physical elements that define the extension of private properties in the public space, increasing the territoriality of the community and the natural surveillance. The hot-spot analysed is surrounded by several elements that define different levels of thresholds and intimacy, such as pavement change (paved-unpaved), porticos (a), drainage system (b), and fences (c) [8]. 


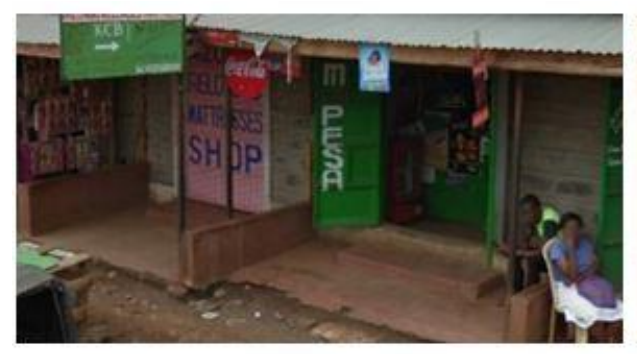

(a)

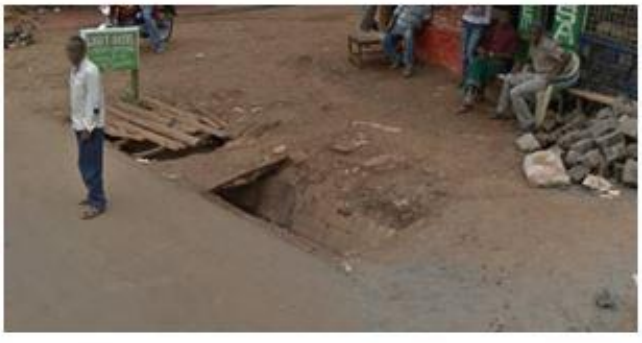

(b)

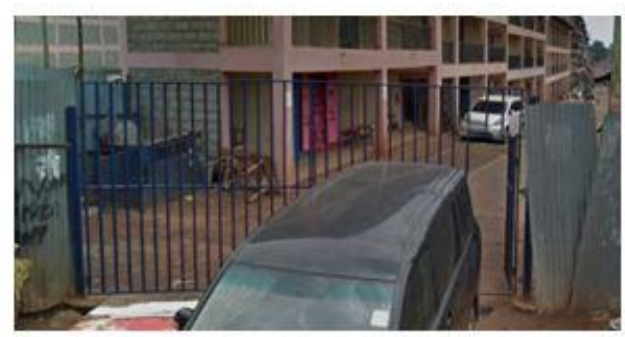

(c)

Figure 13. Hot-spot 1: territoriality elements. Porticos (a), drainage system (b), and fences (c) (source: Google maps street views).

\section{Image and maintenance:}

Buildings. Kibera shanties are built with different techniques and materials: composed metal sheets, wooden structure and heart and cement blocks. This third typology is the most present around the hot-spot, which gives a more decent and respectable image of the public spaces. Moreover, facades are mainly painted and decorated with drawing and information. Generally, the image of this area is well-maintained [70,71].

Pavements. The main street was recently widened and paved by a community upgrading programme in 2015 [70] and has kept decent conditions. However, the thresholds with the buildings are unpaved, dusty and covered with garbage. The drainage system in this area is mostly made by prefabricated cement blocks. However, often garbage is accumulated among the drainage, reducing its efficiency, the hygienic conditions and the overall image of the area.

\subsubsection{Hot-Spot 2}

ID code: 712890340

Note of MapKibera Trust: "People are mugged or killed when they pass there at night." (MapKibera, 2018)

Crime: mugging + murder

Hot-spot classification: Black-spot, with increased risk during the night

Location: the hot-spot is located at the junction of a secondary pedestrian path with Ali Jaden Road (see Figures 14 and 15).

Street conditions: unpaved

Street section: $3.1 \mathrm{~m}$ 


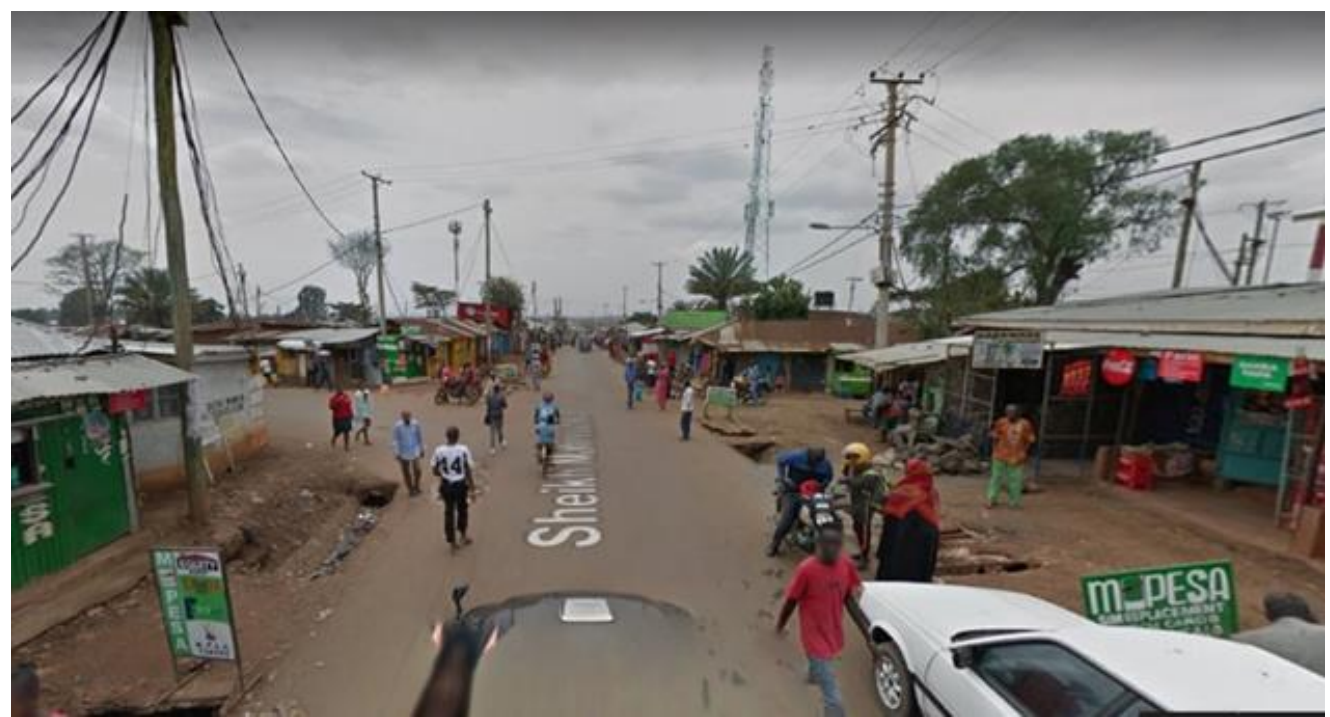

Figure 14. Street view of hot-spot 2 (source: Google maps street views).

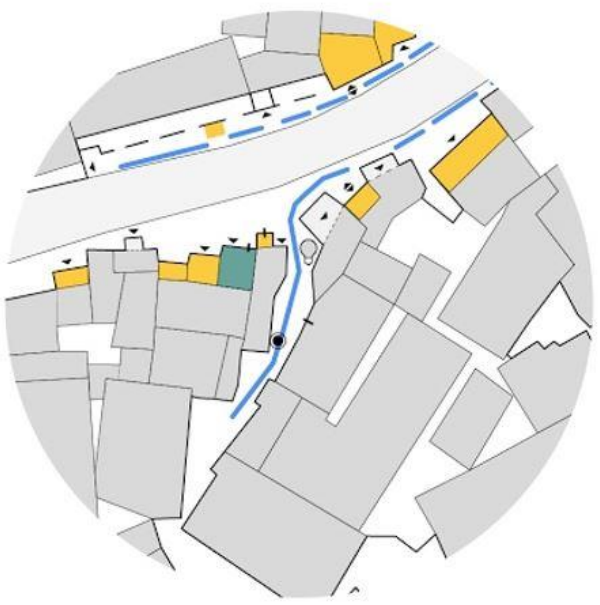

Legend:

Figure 15. Hot-spot 2 (Elaborated by the authors).

Integration (Figure 16): The hot-spot is located on a secondary street with integration value 6 . This aspect confirms Hillier's theories because it is well-connected and adjacent to the high integrated segment but free from natural surveillance [14].

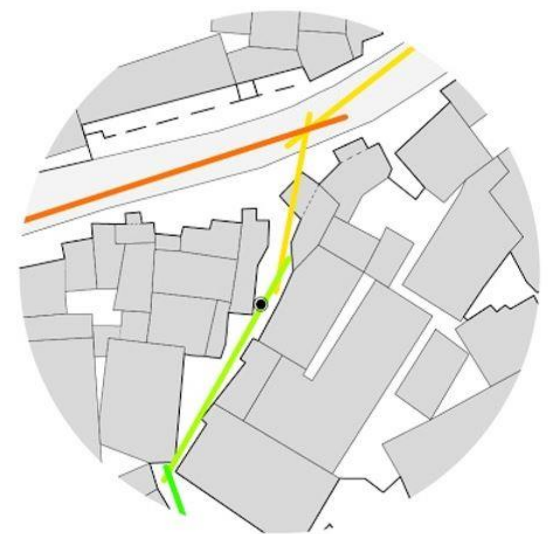

Figure 16. Hot-spot 2: integration map (Elaborated by the authors). 


\section{Illumination (Figure 17):}

Light typology: street light

Light source: four bulbs with different orientation. Bulb body open $>90^{\circ}$

Status: nonoperative

Distance: $15 \mathrm{~m}$

Estimated height: $7.5 \mathrm{~m}$

The typology and the estimated heights show that the hot-spot would fully benefit from the lighting power but it is not operative.

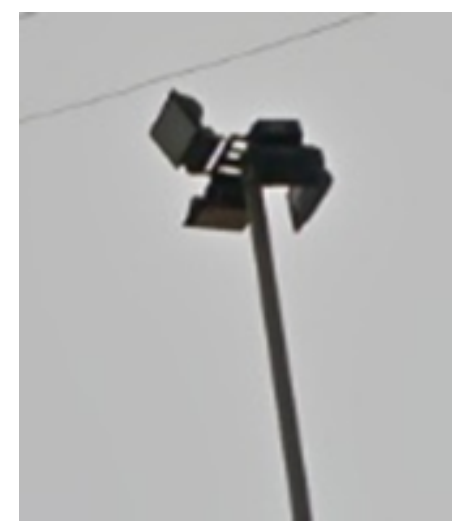

Figure 17. Hot-spot 2: lighting source (source: Google maps street views).

Vitality and diversity: The hot-spot is located on a residential road with almost no public activities that attract people. However, due to its proximity with Ali Jaden Road, one of the main streets that presents several commercial activities, the location benefits from discrete flows of people. Moreover, the street section of Ali Jaden Road directly facing the junction with the secondary road presents an abandoned building which does not provide any natural surveillance.

Active facades (Figure 18): The information related to the facades of the building surrounding the hot-spot is very limited. Street view images show a barred residential window in front of the hot-spot. It is not clear whether the material is transparent or solid; however, one element is not enough to guarantee adequate natural surveillance or discourage criminal actions (isovist angle $=45^{\circ}$ ).

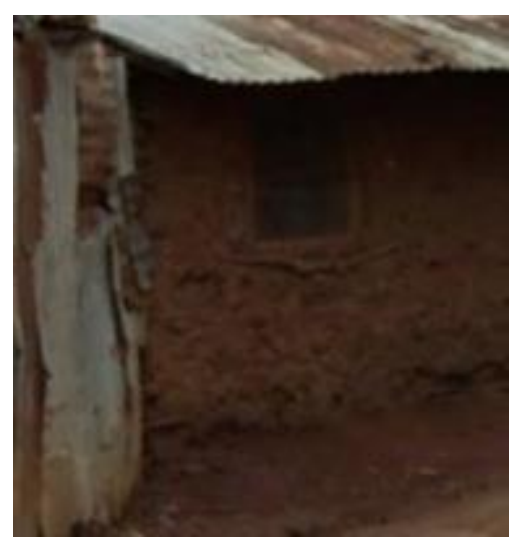

Figure 18. Hot-spot 2: opening typology (source: Google maps street views).

Visibility (Figure 19): Hot-spot visibility from the building's opening is verified by the isovist analysis with Space Syntax. Each opening has a correlated isovist with a specific angle (see angle above). Overlapping the isovists, only a residential window and a commercial activity are directly facing the hot-spot. It is clear that an inadequate number of openings surveil the area to guarantee security. 


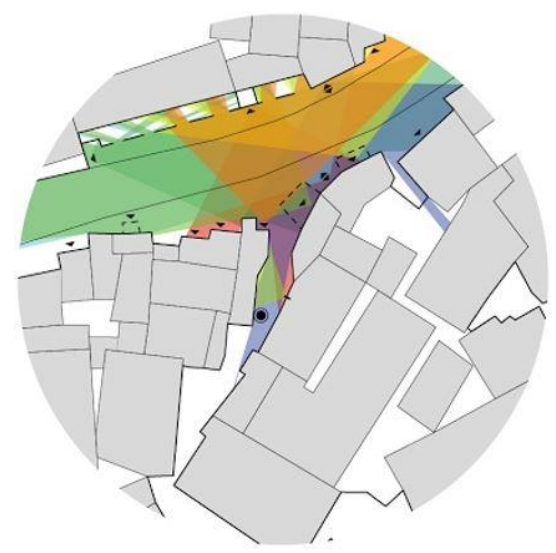

Figure 19. Hot-spot 2: isovists maps (Elaborated by the authors).

Territoriality (Figure 20): The area is surrounded by elements that define thresholds and layers of intimacy, such as the pavement change (paved-unpaved), the drainage system, porticos and the remains of the abandoned building structure. The hot-spot is located in a secondary unpaved road, which represents a more private space in relation to the main space. This space could be related to the residential alley studied by Jacobs and Newman: indeed, it represents an ambiguous space that has a more private dimension, but it is accessible, public and permeable. It benefits from a limited surveillance provided by the scarce people movements and facing windows. It is the most potential location to commit a crime.

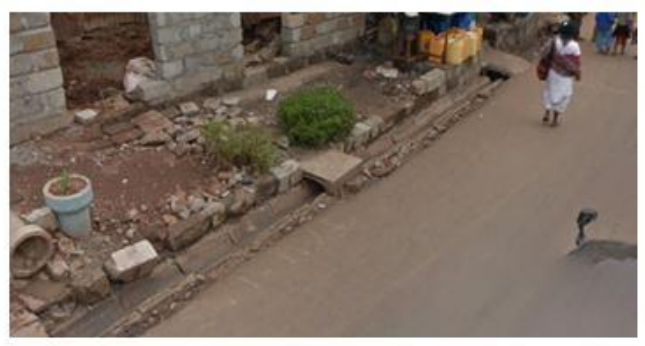

(a)

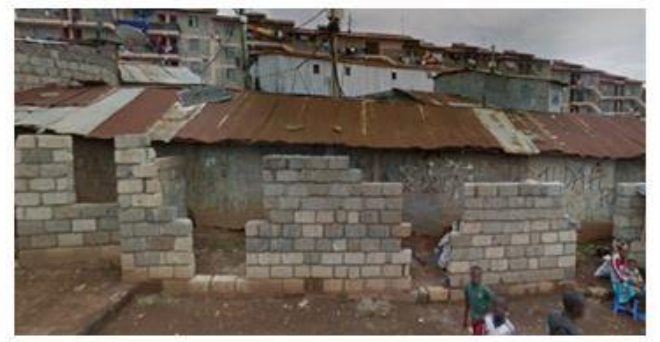

(b)

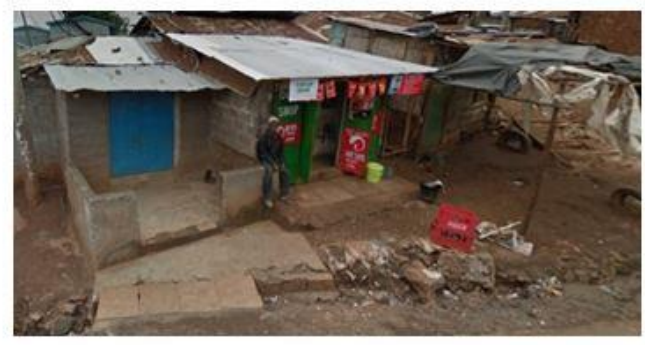

(c)

Figure 20. Hot-spot 2: territoriality elements. Drainage system (a), abandoned building structure (b), and porticos (c) (source: Google maps street views).

\section{Image and maintenance:}

Buildings. In addition, in this case, the building typologies are diverse. The abandoned building decreases the image of this area. In general, the building facades in the secondary street, as they are mainly residential activities, present a lower level of care and decor, in relation to the one in the previous case.

Pavements. The secondary path is unpaved, narrow, irregular, dusty and partially covered by garbage. It presents a drainage line directly digged in the ground which limits the walking comfort and the accessibility of the area. 
Finally, comparing these findings with the territorial analyses, the first hot-spot represents an exception of the main trends, as it is located on a street section with the highest integration value, but it is consistent with the illumination and the visibility criteria. The second hot-spot fully relates with the findings at the territorial scale. Similarly, several linkages can be drawn between the findings of the two hot-spot areas and the criminology theories previously discussed. The first hot-spot benefits from high people flows and a great number of commercial activities with "eyes on the street"; however, the area has great potential for crime occurrence during the night, when all the activities close [7-9]. Regarding the second hot-spot, the area has a moderate risk of crime actions throughout the day, due to the reduced natural surveillance related to the secondary movement flows among this street section [10-13], the presence of an abandoned building facing the area [13], the lack of illumination and the limited number of openings $[7,8]$.

\section{Discussion and Conclusions}

The research focuses on understanding the impact of environmental parameters on the urban security and the distribution of hot-spots within the informal settlement. The analyses described identify some relations between the spatial and configurational features of public spaces and urban security, both at territorial and local scale. However, the research also showcases that environmental components have a great impact on the perception of safety and the use of public space, as also discussed by different authors [6-11,13].

The research isolated and analysed the contribution of each parameter on the patterns of crime in Kibera. However, findings demonstrate that crime occurrence is the result of multiple factors, simultaneously interrelating in space [72]. All these components influence the natural surveillance, which strongly impact crime occurrence and the perception of safety. Thus, the interpretation of each parameter provides more insights if correlated with other factors.

Regarding the parameter of integration, hot-spots in Kibera are mostly located in street section with moderately high integration values. This means that criminals mostly act in secondary streets directly connected with main movement ways, benefitting from good availability of potential targets and a reduced natural surveillance. The results are coherent with Hillier's theories suggesting that antisocial behaviors take place in "the first highly integrated space free from natural surveillance" [66,73,74].

Territorial and local analysis also showed that illumination is an influencing factor for hot-spot location. However, correlating this parameter with the integration value of the street network, a more accurate interpretation is achieved. Specifically, some villages of Kibera, such as Kambi Muri, Kisumu Ndogo, Gatwekera and Raila e Soweto West, are completely without public illumination and the amount of hot-spots in these villages is minor compared to other areas better illuminated. This is probably related to the integration value: most of the street sections are narrow, dark and intricate paths with a low integration value. Then, the movement flow of potential targets is drastically reduced. Thus, criminals in Kibera seem to prioritize street section without illumination that is still close enough to the main movement flows.

Parameters of visibility and active facades show dual and contradictive findings, as also experienced in other studies [75]. However, if correlated with the use of the space and the building's functions (parameter of vitality and diversity), natural surveillance provided by good visibility and active facades drastically changes between day and night.

Finally, factors of territoriality and maintenance influence the perception of safety and the use of the space rather than the crime occurrence in itself. However, they should not be treated as a secondary component while addressing actions for crime prevention [13].

The research encountered several limitations throughout the process, particularly in relation with the reliability of the data sources. Regarding the security data of MapKibera Trust, it should be noted that the voluntary nature of participatory mapping activities limits a systematic data verification [50,51]. In addition, quantitative data such as the number of crime episodes in relation to the hot-spots is missing. However, different experiences and authors demonstrated the importance and the contribution of the 
crowdsourcing platforms in developing strategies for urban security in informal settlements [51,60]. Similarly, data from Space Syntax do not take into consideration some aspects such as the buildings heights, densities and the metric date [76] or the formal and functional dimensions that characterize the urban design and the architecture [77]. From this perspective, this methodology does not capture exceptions and peculiarities of specific contexts, misleading sometimes some interpretations.

The findings have defined some insights for the future of Kibera. The introduction of the Missing Link \#12 will drastically change the spatial configuration, the movement flows and the integration values of the street network of Kibera, as illustrated in Figure 3. The new road is likely to improve the connection of the settlement within the city, resulting in an increment of opportunities for slum dwellers. Patterns of crime will also change, as strongly correlated with the configurational feature of the space and the people movements [14]. This is also testified by Cohen and Felson theory in their effort to explain crime rate changes in the United States between 1947 and 1974: an increment of opportunities and a drastic change in routine activities and movement might impact patterns of crime [12].

The Missing Link \#12 could be a good opportunity for Kibera development, to generate a more vibrant and safer environment. The research suggests some environmental factors that should be taken into consideration, while developing safer public spaces. A holistic approach to deeply understand and tackle these issues is required, where institutional preventive actions, community engagement and physical environment improvements are synergically undertaken [6].

The innovation of the research stands on the intention to integrate and combine different data sources to analyse urban security: in this way, the information elaborated by Space Syntax analyses are complemented by the citizens' empirical experience on a complex topic such as security, often hard to measure and monitor in informal areas. The methodology, currently applied in a real case study, can be also replicated in other slums of Nairobi where MapKibera Trust is already involved in voluntary mapping projects or in different contexts, where participatory efforts are used as a source of data.

Author Contributions: The authors contributed equally. All authors have read and agreed to the published version of the manuscript.

Funding: This research received no external funding.

Acknowledgments: We acknowledge the support given from the CRD-PVS Research and Documentation Centre in Technology, Architecture and City in Developing Countries (Polytechnic of Turin) and from MapKibera Trust in providing data about security in Kibera and time for multiple consultations with the authors.

Conflicts of Interest: The funders had no role in the design of the study; in the collection, analyses, or interpretation of data; in the writing of the manuscript, or in the decision to publish the results.

\section{References}

1. UNODC; UN-HABITAT. Crime Prevention Assessment Tool; United Nation Publication: Nairobi, Kenya, 2009.

2. UNODC. Handbook on the United Nations Crime Prevention Guidelines: Making them Work; United Nation Publication: Nairobi, Kenya, 2010.

3. Reso, S. Assessing Crime Prevention Progress and Making Crime Prevention Assessments from the United Nations Perspective. In Practical Approaches to Urban Crime Prevention, Proceedings of the Workshop at the 12th UN Congress on Crime Prevention and Criminal Justice, International Centre for the Prevention of Crime UNODC, Salvator, Brazil, 12-19 April 2010; United Nations Office on Drugs and Crime: Vienna, Austria, 2011.

4. UN-Habitat. Habitat III issue papers 3-Safer cities. In Proceedings of the Habitat III, United Nations Conference on Housing and Sustainable Urban Development, Quito, Equador, 17-20 October 2016.

5. EFUS. Security, Democracy and City-Co-Producing Urban Security Policies; Manifesto of the European Forum for Urban Security: Paris, France, 2018.

6. UN-Habitat. Enhancing Urban Safety and Security, vol. I, II e III; United Nation Publication: Nairobi, Kenya, 2007.

7. Jacobs, J. Vita e Morte Delle Grandi Città; Piccola Biblioteca Einaudi: Torino, Italy, 2001.

8. Newman, O. Defensible Space, Crime Prevention through Environmental Design; Mac: New York, NY, USA, 1972. 
9. Ray Jeffrey, C. Crime Prevention through Environmental Design; Revised edition; SAGE Publications, Inc.: Beverly Hills, CA, USA, 1977.

10. Brantingham, P.J.; Brantingham, P.L. Environmental Criminology; Waveland Press: Prospect Heights, IL, USA, 1991.

11. Brantingham, P.J.; Brantingham, P.L. Crime Pattern Theory. Lecture at Institute for Canadian Urban Research Studies. 2018. Available online: https://www.scribd.com/document/86908463/Crime-PatternTheory (accessed on 10 February 2020).

12. Cohen, L.E.; Felson, M. Social Change and Crime Rate Trends: A Routine Activity Approach. American Sociological Review, 588-608. 1979. Available online: https://www.jstor.org/stable/2094589 (accessed on 1 March 2020).

13. Kelling, G.; Cole, C. Fixing Broken Windows: Restoring Order and Reducing Crime in Our Communities; Free Press: New York, NY, USA, 1997.

14. Hillier, B. Space is the Machine; University College: London, UK, 2004; pp. 138-171.

15. Friendly, M. The Life and Works of André-Michel Guerry (1802-1866); York University: Toronto, ON, Canada, 2007.

16. Cho, J.T. Exploring the effects of CCTV upon fear of crime: A multi-level approach in Seoul. Int. J. Law Crime Justice 2017, 49, 35-45. [CrossRef]

17. Fitzpatrick, A. Up in the Air. Applying the Jacobs Crowd Formula to Drone. In Proceedings of the Humanitarian Technology: Science, Systems and Global Impact, Cambridge, MA, USA, 12-14 May 2015.

18. PredPol. Available online: https://www.predpol.com/ (accessed on 15 December 2018).

19. Shotspotter. Available online: https://www.shotspotter.com/missions/ (accessed on 15 December 2018).

20. The Problem of Predictive Policing. Available online: https://hrdag.org/usa/ (accessed on 15 December 2018).

21. Predictive Crime Software. Available online: https://nova.ilsole24ore.com/esperienze/software-per-prevenireil-crimine/ (accessed on 15 December 2018).

22. Prison Policy Report. Available online: https://www.prisonpolicy.org/reports/rates.html (accessed on 15 December 2018).

23. PredPol. Available online: https://www.focus.it/tecnologia/innovazione/predpol-il-softwareche-prevede-ilcrimine-21012013-78554 (accessed on 15 December 2018).

24. Whitzman, C. The effectiveness of women's safety audits. Secur. J. 2009, 22, 205-218. [CrossRef]

25. Kamau, H. Safety Audits, the Kenyian experience. In Proceedings of the First International Seminar on Women's Safety-Making the Links, Montreal, QC, Canada, 9-11 May 2002.

26. Hagan, M. Safe. Mathare A Mobile System for Women's Safe. Commutes in the Slums. In Proceedings of the MobileHCI'12, San Francisco, CA, USA, 21-24 September 2012.

27. UN-Habitat. Kenya Slum Upgrading Programme: Strategy Document; United Nation Publication: Nairobi, Kenya, 2003.

28. De Filippi, F.; Coscia, C.; Boella, G.; Antonini, A.; Calafiore, A.; Cantini, A.; Guido, R.; Salaroglio, C.; Sanasi, L.; Schifanella, C. MiraMap: A We-Government Tool for Smart Peripheries in Smart Cities. IEE Access 2016, 4, 3824-3843. [CrossRef]

29. De Filippi, F.; Coscia, C.; Guido, R. How Technologies Can Enhance Open Policy Making and Citizen-responsive Urban Planning. Int. J. E-Plan. Res. (IJEPR) 2017, 6, 23-42. [CrossRef]

30. De Filippi, F.; Coscia, C.; Guido, R. Miramap: A collective awareness platform to support open policy making and the integration of the citizens' perspective in urban planning and governance. In Technologies for Development; Hostettler, S., Najih Besson, S., Bolay, J.C., Eds.; Springer International Publishing: New York, NY, USA, 2017.

31. Linking Perceptions of Safety to Infrastructural Upgrading in Informal Settlements. Available online: http://mappingnobigdeal.com/2017/01/07/linking-perceptions-of-safety-to-infrastructural-upgrading-ininformal-settlements/ (accessed on 28 June 2018).

32. Ushaidi. Available online: https://www.ushahidi.com/ (accessed on 10 July 2018).

33. Jiří Pánek. Mapping citizens' emotions: Participatory planning support system in Olomouc, Czech Republic. J. Maps 2019, 15, 8-12. [CrossRef]

34. Safetpin. Available online: http://safetipin.com/ (accessed on 22 July 2018).

35. Fixmystreet. Available online: https://www.fixmystreet.com/ (accessed on 25 July 2018). 
36. De Filippi, F. Slum[e]scape: A Challenge for Sustainable Development Projects; Alinea: Firenze, Italy, 2009; pp. 10-34.

37. UN-Habitat. The Challange of Slums; United Nation Publication: Nairobi, Kenya, 2003.

38. Roberts, M.J. Conflict analysis of the 2007 post-election violence in Kenya. In Managing Conflicts in Africa's Democratic Transitions; Lexington Books: Washington DC, USA, 2009.

39. Elections Crimes and Offences in Kenya. Available online: https://crimeresearch.go.ke/election-crimes-andoffences-in-kenya/ (accessed on 3 November 2018).

40. Safer Cities Programme; UN-Habitat. Crime in Nairobi Results of a City Wide Victim Survey; United Nation Publication: Nairobi, Kenya, 2002.

41. Davis, M. The Planet of Slums, 3rd ed.; Verso: London, UK, 2016; pp. 10-56.

42. Neuwirth, R. Shadow Cities: A Bilion Squatter, a Urban. New World; Fusi Orari: Roma, Italy, 2007.

43. Rahbaran, S.; Herz, M. Nairobi Kenya, Migration Shaping the City, 1st ed.; Lars Muller Publishers: Basel, Switzerland, 2014; pp. 7-32.

44. Marras, S. Mapping the Unmapped. Ph.D. Thesis, Department of Sociology and Social Research, University of Milan, Milan, Italy, 2010.

45. Desgroppes, A.; Taupin, S. Kibera: The Biggest Slum in Africa? Les Cahiers d'Afrique de l'Est 2012, 44, $23-33$.

46. Uhuru Issues Title Deed to Kibra Nubians. Available online: https://www.nation.co.ke/news/Uhuru-issuestitle-deed-to-Kibra-Nubians/1056-3953204-9jfwvk/index.html (accessed on 12 November 2018).

47. Division or Development? Missing Link \#12: A New Road through Kibera. Available online: http: //blog.kounkuey.org/ (accessed on 11 August 2018).

48. Annual Crime Report in Kenya, 2018. Available online: http://www.nationalpolice.go.ke/crime-statistics.html (accessed on 21 February 2020).

49. Martinuzzi, C.; De Filippi, F.; Cocina, G.G. La sicurezza urbana a Kibera prima e dopo la costruzione del Missing Link \#12: Integrazione della mappatura partecipativa di MapKibera Trust e delle analisi configurazionali di Space Syntax. Master's Thesis, Department of Architecture and Design, Polytecnic of Turin, Turin, Italy, 2019.

50. Silva, C.N. Citizen-Responsive Urban. E-Planning: Recent Developments and Critical Perspectives; IGI Global: Hershey, PA, USA, 2020. [CrossRef]

51. Rzeszewski, M.; Kotus, J. Usability and usefulness of internet mapping platforms in participatory spatial planning. Appl. Geogr. 2019, 103, 56-69. [CrossRef]

52. Armana, F.; Angelab, J. Mobile participation (mParticipation) in urban development: The experience of FlashPoll app in Berlin (Germany). Inf. Polity 2019, 24, 199-222.

53. Rains, E.; Krishna, A.; Wibbels, E. Combining satellite and survey data to study Indian slums: Evidence on the range of conditions and implications for urban policy. Environ. Urban. 2018. [CrossRef]

54. Falco, E.; Zambrano-Verratti, J.; Kleinhans, R. Web-based participatory mapping in informal settlements: The slums of Caracas, Venezuela. Habitat Int. 2019, 94, 102038. [CrossRef]

55. Hagen, E. Mapping Change, community information empowerment in Kibera. In Innovations: Technology, Governance, Globalization; MIT Press: Cambridge, MA, USA, 2011; Volume 6, pp. 69-94.

56. Goodchild, M. Citizens as Sensors: The world of Volunteered Geography. GeoJournal 2007, 69, $211-221$. [CrossRef]

57. Security Mapping. Available online: www.mapkiberatrust.org (accessed on 23 March 2018).

58. Demartis, E. Geografie per la pace e la Cooperazione allo Sviluppo. Mappare e Prevenire le Violenze e i Disordini Post-Elettorali Negli slum di Nairobi: Un Progetto di ICT4D Partecipativo. Master's Thesis, Department in Economy and Statistic, University of Torino, Torino, Italy, 2013.

59. Gonzales, R.; Schofield, R.; Hart, S. Mapping Crime: Understanding Hot Spots. U.S. Department of Justice, Office of Justice Programs, National Institute of Justice, Special Report. Available online: www.ojp.usdoj. gov/nij (accessed on 23 February 2020).

60. Hagen, E. Open Mapping from the Ground up: Learning from Map Kibera; Making All Voices Count Research Report; IDS: Brighton, UK, 2017.

61. Hillier, B.; Hanson, J. The Social Logic of Space; Cambridge University Press: Cambridge, UK, 1984.

62. Hillier, B.; Iida, S. Network and Psychological Effects in Urban. Movement. In COSIT 2005: Spatial Information Theory; Cohn, A.G., Mark, D.M., Eds.; Lecture Notes in Computer Science; Springer: Berlin/Heidelberg, Germany, 2005; Volume 3693. 
63. Cocina, G.G. Cultural needs in hospital humanization. In Proceedings of the Caumme III/PAUMME International Symposium "Migration and the Built Environment in the Mediterranean and the Middle Est", Napoli, Italy, 24-26 November 2016; ISBN 978-886-975-154-7.

64. Cocina, G.G. Responding to user cultural needs in hospitals with the support of Space Syntax Analysis. In Proceedings of the 11th International Space Syntax Symposium, Lisbon, Portugal, 3-7 July 2017.

65. Setola, N. Percorsi, Flussi e Persone Nella Progettazione Ospedaliera. L'analisi Configurazionale, Teoria e Applicazione; Firenze University Press: Firenze, Italy, 2013.

66. Hillier, B. Can. streets be made safe? Urban Des. Int. 2004, 9, 31-45. [CrossRef]

67. Slum Lighting Initiative of Adopt-a-light Limited. Available online: http://www.adopt-a-light.com/about_us. php (accessed on 21 August 2018).

68. The Steadman Group. An Evaluation of the Lighting Initiative in Nairobi Slums; Steadman Group: Nairobi, Kenya, 2006.

69. Tarkhanyan, L. Drug crime and the urban Mosaic: The location choice of drug crime in relation to high streets, bars, schools and hospitals. In 9th International Space Syntax Symposium; University College London: London, UK, 2013.

70. Mitra, S.; Mulligan, J.; Schilling, J.; Harper, J.; Vivekananda, J.; Krause, L. Developing risk or resilience? Effects of slum upgrading on the social contract and social cohesion in Kibera, Nairobi. Environ. Urban. 2017, 29, 103-122. [CrossRef]

71. UN-Habitat. Building Urban Safety through Slum Upgrading; United Nation Publication: Nairobi, Kenya, 2011.

72. Dzamydiene, D.; Rudzkiene, V. Multiple Regression Analysis in Crime Pattern Warehouse for Decision Support. In Database and Expert Systems Applications: 13th International Conference, DEXA 2002, Aix-en-Provence, France, 2-6 September 2002; Springer: Berlin/Heidelberg, Germany, 2003; pp. 249-258.

73. Hillier, B.; Sahbaz, O. An. Evidence Based Approach to Crime and Urban Design or, Can We Have Vitality, Sustainability and Security all at once? Bartlett School of Graduate Studies: London, UK, 2008.

74. Hillier, B.; Sahbaz, O. High. Resolution Analysis of Crime Patterns in Urban. Street Networks: An Initial Statistical Sketch from an Ongoing Study of a London Borough; University College: London, UK, 2005.

75. Lee, S.; Ha, M. The Duality of Visibility: Does Visibility Increase or Decrease the Fear of Crime in Schools' Exterior Environments? Yonsey University: Seul, Korea, 2014.

76. Ratti, C. Urban. texture and space syntax: Some inconsistencies. Environ. Plann. B Plan. Des. 2004, 31, 487-499. [CrossRef]

77. Seamon, D. A Life of the Place: A Phenomenological Commentary on Bill Hillier's Theory of Space Syntax. Nordic J. Acad. Res. 1994, 7, 1. 